\title{
Semi-automated detection of looting in Afghanistan using multispectral imagery and principal component analysis
}

\author{
Anthony Lauricella ${ }^{1, *}$, Joshua Cannon ${ }^{1}$, Scott Branting ${ }^{2}$ \\ \& Emily Hammer ${ }^{1}$
}

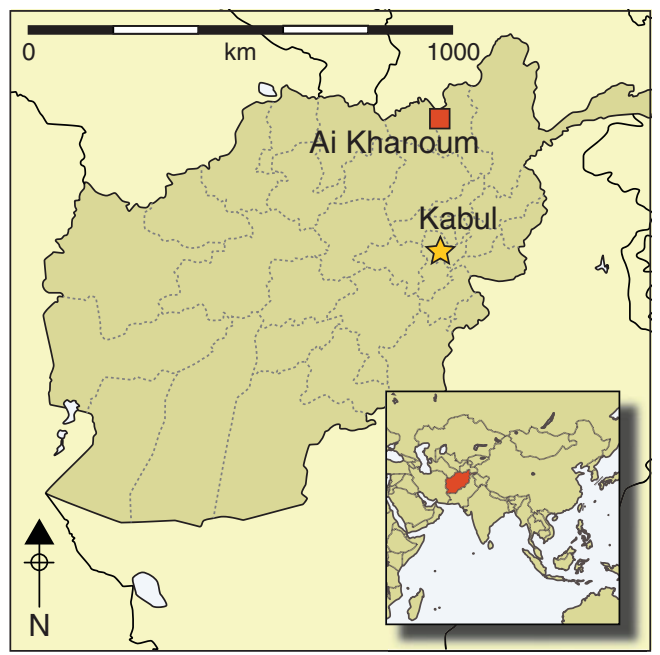

High-resolution satellite imagery has proved to be a powerful tool for calculating the extent of looting at heritage sites in conflict zones around the world. Monitoring damage over time, however, has been largely dependent upon laborious and error-prone manual comparisons of satellite imagery taken at different dates. The semi-automated detection process presented here offers a more expedient and accurate method for monitoring looting activities over time, as evidenced at the site of Ai Khanoum in Afghanistan. It is hoped that this method, which relies upon multispectral imagery and principal component analysis, may be adapted to great effect for use in other areas where heritage loss is of significant concern.

Keywords: Afghanistan, multispectral imagery, satellite imagery, principal component analysis, heritage preservation, looting

\section{Introduction}

Commercial high-resolution satellite imagery has become a powerful tool in the field of cultural heritage. This imagery allows researchers to confirm the location of published sites, as well as to locate and document new sites. Many collaborative projects documenting looting and other forms of destruction to archaeological sites in areas of Syria and Iraq controlled by the so-called Islamic State, and in other zones of conflict across North Africa and the Middle East, employ visual analysis of such imagery (e.g. Cunliffe 2013; Bjørgo et al. 2014; Wolfinbarger et al. 2014; Al Quntar et al. 2015; Casana 2015; Stein 2015;

1 The Oriental Institute, University of Chicago, 1155 E 58 th Street, Chicago, IL 60637, USA

2 Anthropology Department, University of Central Florida, 4297 Andromeda Loop N, Orlando, FL 32816, USA

*Author for correspondence (Email: ajlauricella@uchicago.edu) 
Parcak et al. 2016). Quantitative data on looting coverage and changes in looting over time remain difficult to collect, however, because individuals need training to examine imagery and trace disturbances in the surface of a site. Here we present a methodology that significantly improves the speed and accuracy of the analysis of remote sensing data for heritage documentation. This is achieved through the semi-automated detection of looters' pits using multispectral satellite imagery.

Our method consists of a two-step process, carried out using GIS software, and tested on the site of Ai Khanoum in Afghanistan (Figure 1). First, principal component analysis (PCA) was used to isolate areas of an image that have a spectral signature similar to that of looters' pits that have already been identified on pansharpened imagery. This first step produces many false positives that correspond to other types of depressions in the surfaces of the sites. The second step excludes these false positives by using empirically established geometric properties of looters' pits to exclude these false positives. The final results give an image of the site with polygons marking individual looting pits. From these, the number of pits and the spatial extent of looting can be calculated. The power of our method lies in its ability to facilitate quick, quantitative measures of looting over time while keeping in step with any new release of satellite imagery.

\section{Use of remote sensing to monitor looting patterns}

Satellite imagery and GIS technology have transformed our ability to monitor and prevent the destruction of archaeological sites (Contreras 2010; Contreras \& Brodie 2010; for a recent review, see Hritz 2014: 252-55). The correlation between conflict, weak governmental infrastructure and looting makes it, in many cases, nearly impossible for archaeologists or cultural heritage professionals to monitor threatened sites on the ground. Satellite imagery has offered an important solution to this problem, particularly as it has increased in spatial and temporal coverage. Images are taken with increasing frequency, sometimes only hours or days apart, allowing archaeologists to observe some types of ongoing or potential future damage, and even assess the level of group organisation behind this damage. In southern Iraq, a time-series of high-resolution imagery has enabled cumulative quantification of looting holes at individual sites since the 2003 invasion, as well as analysis of regional spatial patterns in the sites that have been targeted for looting (Hritz 2008; Stone 2008; Hanson 2011, 2012: 150-80). A team led by Van Ess focusing on the site of Uruk has attempted to automate the process of identifying looting events in satellite imagery, but using different data, software and modelling approaches to those we employ. This team used panchromatic IKONOS satellite imagery and object-oriented image analysis software (Definiens Developer) to identify archaeological sites, architecture and looting pit clusters through similarity to previously identified objects, or through a list of parameters determined by the developers (Van Ess et al. 2006: 671, 673-74). Researchers have also used combinations of high-resolution imagery and spatial autocorrelation statistics to monitor sites in Peru (Lasaponara \& Masini 2010; Lasaponara et al. 2014).

Drones and photogrammetric methods now provide an alternative method for identifying looting at sites that are outside conflict zones and may be accessed. Images captured from drones can be used to produce 3D models of archaeological sites with a 


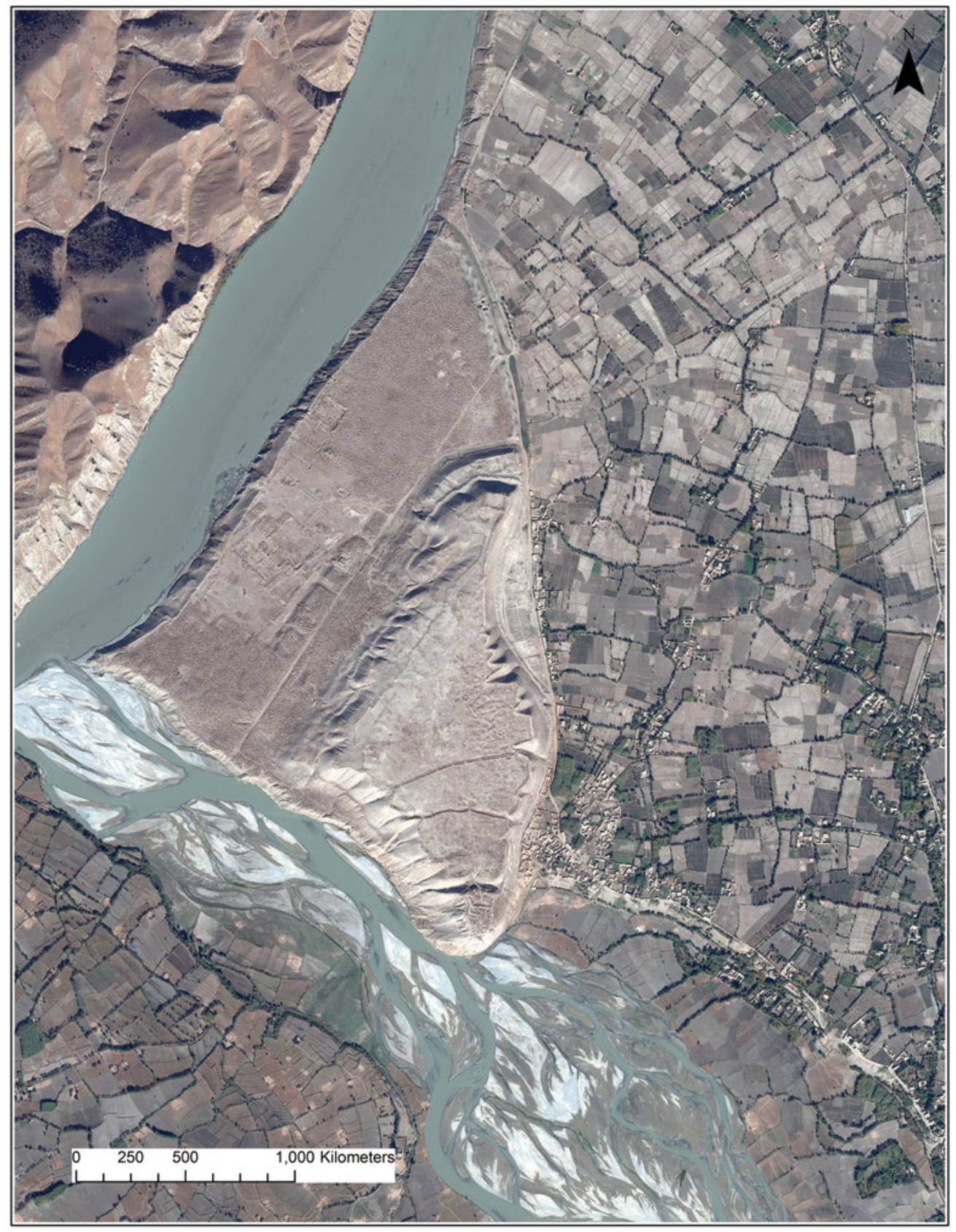

Figure 1. The archaeological site of Ai Khanoum, in Takhar Province, north-eastern Afghanistan. (WorldView-2 imagery, dated 8 November 2010.)

(C) Antiquity Publications Ltd, 2017 
resolution of 10-20mm per pixel (e.g. Hill et al. 2014; Kersel \& Hill 2015). Aerial mapping at the site of Fifa in Jordan allowed the excavators to document looting pits that targeted individual burials, and this method, in the future, could even allow the volume of these pits to be measured (Salopek 2014). Similarly, a combination of high- and medium-resolution imagery was used in conjunction with $3 \mathrm{D}$ structure-from-motion images generated from pole-mounted ground photography to monitor damage to geoglyphs in coastal Peru (Hesse 2015).

The above case studies, as well as recent collaborative projects tracking looting in Syria and Iraq, have relied on panchromatic imagery and manual methods for counting and measuring looters' pits. Some of the studies mapped thousands of individual pits via these time-consuming methods, and some of the collaborative projects have had to reassess looting on a monthly basis. It is useful to automate the process of identifying looters' pits, especially given the large number of sites continuously targeted for looting in some conflict zones and the increasing availability of satellite imagery taken over shorter time intervals.

Multispectral imagery has not yet been employed for monitoring looting patterns, but provides an avenue for semi-automated detection. Additional bands measuring reflectance of non-visible wavelengths of light allow for analyses that can highlight particular landscape features or characteristics such as vegetation and soil type. The availability of such datasets has led archaeologists to pursue spectral-based (as opposed to object-based) automated methods for detecting archaeological sites (e.g. Altaweel 2005; Saturno et al. 2007; Menze $\&$ Ur 2012). The choice to replace trained human analysts has been critiqued (Casana 2014), but manual methods cannot keep pace with the rapid accumulation of imagery, and automated detection systems will become increasingly essential. Furthermore, the inclusion of search parameters based on human-generated observations will help to overcome some of the pitfalls of automated detection.

\section{A semi-automated method for detecting looters' pits}

While archaeological sites are constantly subject to a variety of threats, both natural and anthropogenic, looting is one of the more destructive types, as it endangers the physical integrity of the site and inhibits future scientific investigation. Furthermore, unlike other forms of damage, looting helps to support illicit markets built upon detrimental attitudes towards heritage conservation. Cultural heritage scholars and archaeologists must be able to identify threatened sites in order to prioritise resources for preservation and damage mitigation. We employed high-resolution multispectral imagery from the WorldView-2 satellite for the automated detection and mapping of looters' pits. Launched in 2009, this is the first satellite to collect high-resolution multispectral data (with an optimal resolution of $1.85-2.07 \mathrm{~m}$ per pixel, and eight total bands) (DigitalGlobe Corporation 2013). While panchromatic images from some DigitalGlobe satellites including WorldView-2 have been made freely available through Google Earth, Bing Maps and other platforms, multispectral versions of WorldView-2 images must be purchased.

Individual pits and disturbances are clearly visible on panchromatic WorldView-2 images, especially after pansharpening. The process of pansharpening is a common datafusion technique that upsamples the spectral bands to the higher resolution of the 
panchromatic image. We used the Hyperspherical Color Transform preset in the ERDAS Imagine software, which is recommended for WorldView-2 imagery, but it is also possible to pansharpen imagery using different methods in ArcGIS and other software. Conversion to Top of Atmosphere Reflectance following the method described by DigitalGlobe ensured that pixel values more accurately represent the spectral radiation received by the satellite (DigitalGlobe Corporation 2010), rather than the original digital number. This process was carried out using the ArcGIS Raster Calculator.

\section{Step 1. Isolating features with certain spectral properties}

To isolate features in the image with spectral properties similar to those of looters' pits, we applied PCA to multispectral imagery. PCA is a statistical method used in the analysis of multivariate datasets. Given an input with $x$ number of dimensions, PCA reorders the dataset into $x$ new outputs that account for the most variance within the whole dataset. In the case of multispectral satellite imagery, PCA can recombine data collected on the reflectance of visible and non-visible spectra of light, highlighting patterns in the landscape (Lillesand et al. 2004: 536-40). When the PCA input is an eight-band multispectral satellite image, the output consists of eight raster images that express decreasing amounts of variability in the dataset.

Experimentation with multispectral images for several archaeological sites in Afghanistan and Jordan showed that the fourth principal component displays looting pits most distinctively. While pit features are visible on all bands and components, they are particularly well contrasted from their surroundings in the fourth component raster (Figure 2). The fourth component raster appears well suited to large mounded sites lacking significant foliage cover. This fits many sites in the Near East, although other landscapes may be better described by different components. Using the Interactive Supervised Classification tool in ArcGIS, we defined training polygons on a pit, a spoil heap and an area of bare earth within the fourth principal component raster to specify pixel values of different classes. This classification isolates pixels corresponding to pits, which can be converted into polygons representing their location and extent. Inspection of PCA rasters produced from images taken in different seasons (wet and dry) suggests that the method is not greatly affected by moisture content, although data in the multispectral bands may be affected by other environmental or atmospheric variables. As with most detection methods, ours benefits from a clear contrast between the site and its surrounding landscape.

Not every pixel or group of pixels flagged by this process corresponds to a looting pit. Other features with negative topography in the landscape, such as irrigation canals and large pits created by mining, construction or other earth-working activities, often have spectral properties similar to looters' pits, and are also highlighted by the analysis. These constitute the false positives mentioned in the introduction.

\section{Step 2. Excluding false positives using geometric properties}

We excluded false positives produced by the PCA and supervised classification using geometric properties (size and shape) common to most looters' pits. Many false positives are too small or too large to correspond to a pit dug by hand, and can easily be eliminated.

(C) Antiquity Publications Ltd, 2017 


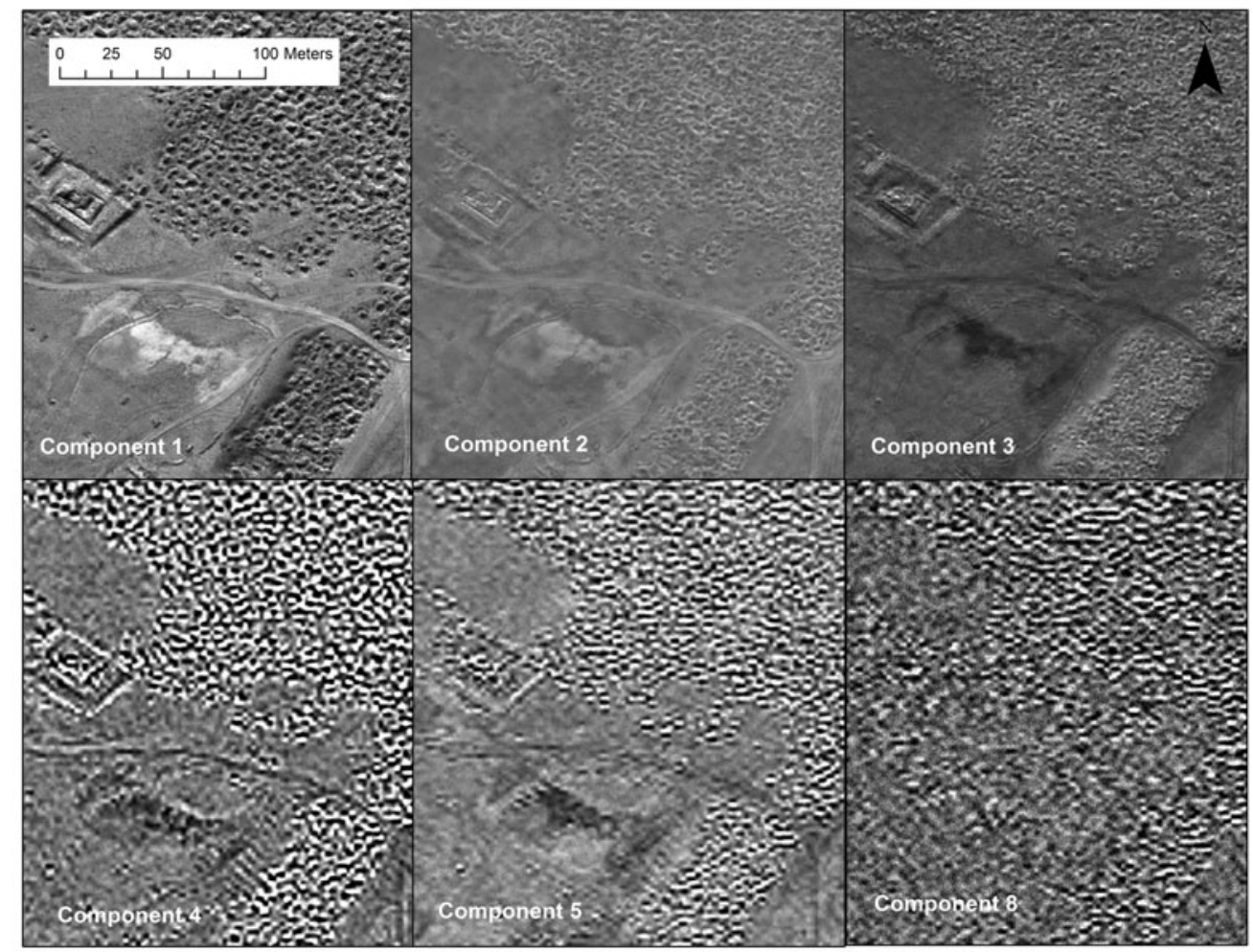

Figure 2. Satellite imagery showing part of the site of Ai Khanoum in Afghanistan. The six boxes show different features highlighted by each component of the principal components analysis. Note that looters' pits are most clearly contrasted with their surroundings in component 4. Higher components have diminishing clarity. (WorldView-2 imagery, dated 8 November 2010.)

Other false positives do not take a shape common to most looting pits and can be excluded on the basis of their geometry. An index of circularity equal to $4 \pi^{*}$ area/perimeter ${ }^{2}$ allows the removal of improbable shapes, particularly long, linear features such as ditches or canals that do not usually represent looting.

Reasonable thresholds for excluding false positives were established using measurements from known looted sites across the Middle East and farther afield as a reference. Polygons were manually drawn around thousands of looters' pits visible on high-resolution satellite imagery, and we then examined patterns in the geometric properties of these polygons in order to investigate pit size and the characteristics of these intrusions. The sample of sites was chosen to include a variety of landscapes, periods and patterns of looting, so that the observations would not be restricted to the specifics of a particular time or location. At the sites in our sample, Ai Khanoum (Afghanistan), Qarawal Tepe (Afghanistan), Isin (Iraq), Umma (Iraq), Fifa (Jordan) and Cahuachi (Peru), the area of the pits ranges from 2.9$10.49 \mathrm{~m}^{2}$. Average pit perimeters range from $6.79-12.1 \mathrm{~m}$, while circularity indices range from $0.60010-0.835796$. These observations (Table 1) could serve as a starting point for future analyses. 
Table 1. Geometric properties of looters' pits at six archaeological sites.

\begin{tabular}{lccc}
\hline Site & Average pit area $\left(\mathbf{m}^{2}\right)$ & Average pit perimeter $(\mathbf{m})$ & Average circularity index \\
\hline & & & \\
Ai Khanoum & 10.49 & 12.10 & 0.819904 \\
Qarawal Tepe & 11.82 & 12.15 & 0.821235 \\
Umma & 3.38 & 6.79 & 0.674484 \\
Isin & 7.76 & 11.88 & 0.649762 \\
Fifa & 2.91 & 7.75 & 0.60010 \\
Cahuachi & 7.05 & 9.68 & 0.835796 \\
\hline
\end{tabular}

\section{Application of the method to Ai Khanoum, Afghanistan}

The history of looting in Afghanistan has remained understudied in comparison to other conflict zones in Syria, Iraq and Egypt. Since 2012, the Oriental Institute of the University of Chicago has collaborated with Afghan partners to carry out cultural heritage projects in Afghanistan (Stein 2015). The Afghan Heritage Mapping Partnership focuses on documenting patterns of looting across the country, and requires quantification of the intensity of looting at individual sites. The scale of this endeavour inspired the development of a semi-automatic methodology for detecting looters' pits. The possibilities and success of the semi-automated methodology are illustrated by the results of our analysis of the site of Ai Khanoum in Takhar Province, Afghanistan (Figure 1). This 205 ha site was probably the location for the city of Alexandria-on-theOxus, one of the primary cities of the Graeco-Bactrian kingdom, and was excavated in the 1960s and 1970s (Bernard 1967; Martinez-Seve 2014). The size of the site, its clear boundaries and its history of looting made it an ideal first candidate for analysis.

Following the PCA and supervised classification, the empirically established geometric ranges from Ai Khanoum were applied to restrict the polygon file to a group of features most likely to represent looters' pits. We excluded features whose surface area was more than one standard deviation above and below the mean, as well as features whose circularity index was more than one standard deviation below the mean.

A comparison of the number of hand-drawn pits and computer-generated polygons shows that the semi-automated method registers 2364 pits as opposed to 2156 hand-drawn pits in test areas (Figures $3 \& 4$ ). The larger number of polygons comes not only from some remaining false positives, but also from some singular pits appearing as multiple polygons in the analysis raster. The total area of the pits identified by the automated method was $16801 \mathrm{~m}^{2}$ in comparison to a manually calculated total area of $22306 \mathrm{~m}^{2}$. The method also produces false negatives. Results show that at Ai Khanoum the automated method is less likely to detect shallow pits and pits located on the slopes between the different levels of the site. This means that older pits may have a higher chance of escaping detection, although at Ai Khanoum, the majority of pits appear to be quite deep. While some looting pits are not highlighted, and some legitimate polygons are removed in the exclusion process, the results, in aggregate, give a reasonable metric for looting at the site.

(C) Antiquity Publications Ltd, 2017 


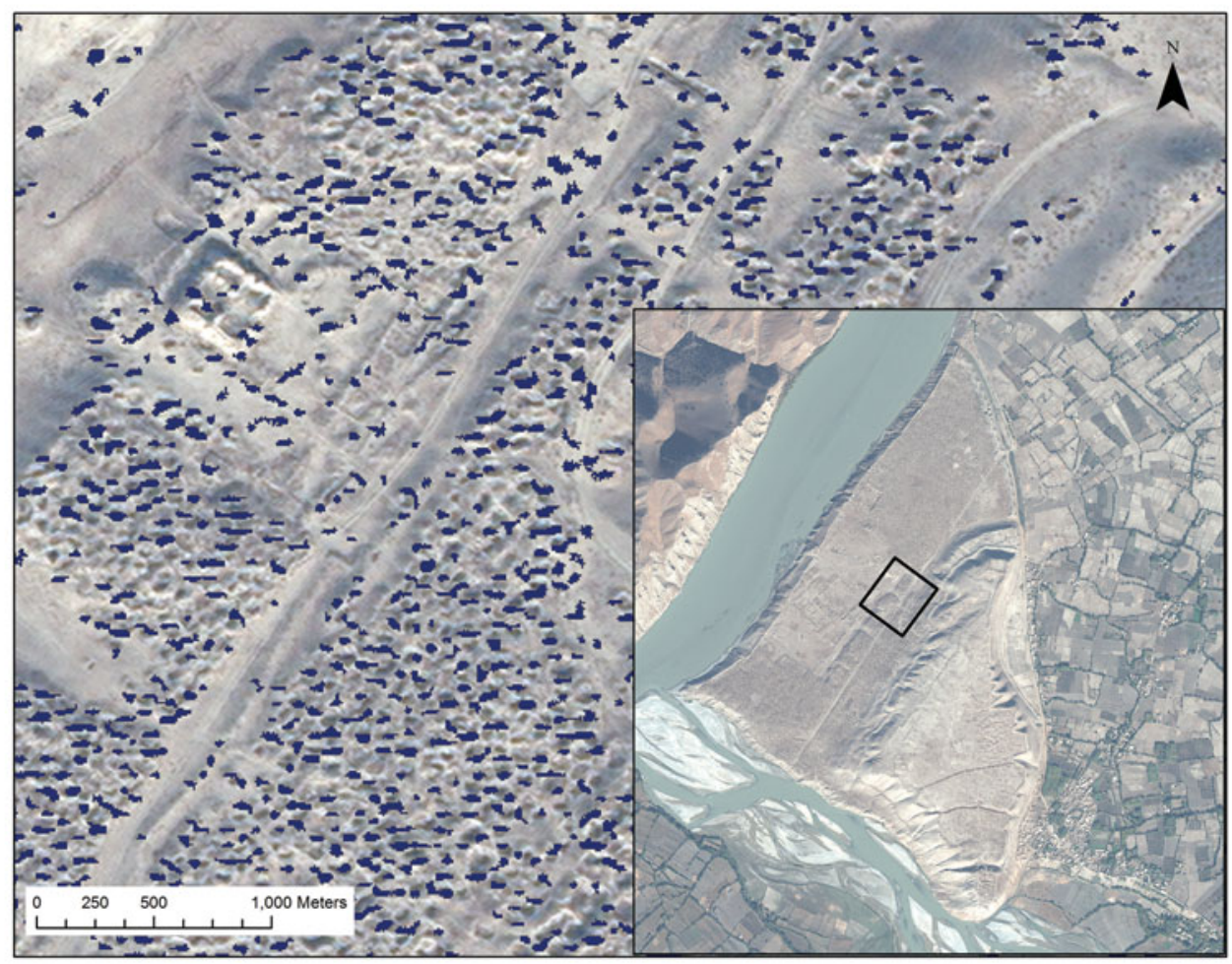

Figure 3. Pit polygons modelled with interactive, supervised classification of principal component raster at the site of Ai Khanoum, Afghanistan. Inset: the location of the area of the site shown in the figure. (WorldView-2 imagery, dated 8 November 2010.)

The method allows us to quantify the amount and intensity of looting at Ai Khanoum to an extent that would be impossible using manual methods (Figures $3 \& 4$ ). Using the procedures described above, we conclude that the number of looting pits at Ai Khanoum was 21095 in November 2010. The total surface area of the pits is estimated at $149041 \mathrm{~m}^{2}$, representing approximately 17 per cent of the surface area of the site. This study is the first quantitative characterisation of the extent of looting at Ai Khanoum, and provides a baseline for determining whether looting has continued at the site since 2010.

\section{Discussion and conclusions}

We have explained and demonstrated the success of a semi-automated methodology that uses multispectral satellite imagery to automate the detection of looters' pits on the surface of sites in Afghanistan. The method uses PCA and empirically established geometric properties to identify and measure individual pits. It allows for a much more rapid quantification of looting patterns than visual inspection, and uses pre-built functions found

(C) Antiquity Publications Ltd, 2017 


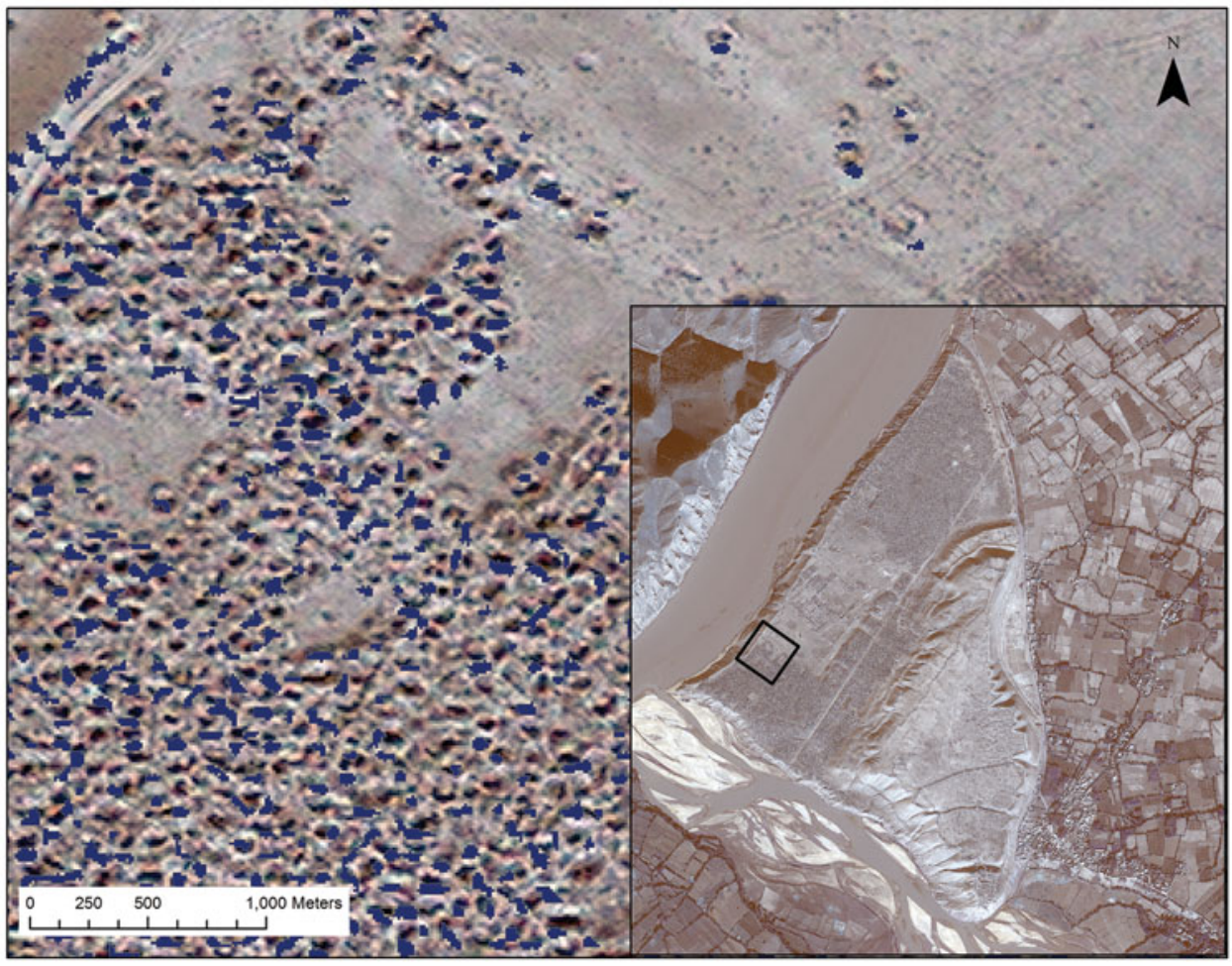

Figure 4. Pit polygons modelled with interactive, supervised classification of principal component raster at the site of Ai Khanoum, Afghanistan. Inset: the location of the area of the site shown in the figure. (WorldView-2, dated 8 November 2010.)

in commonly available GIS software. PCA outputs can be generated easily in ArcGIS or open-source equivalents, and the geometric calculations are very basic. PCA has been used previously at a regional scale to identify archaeological sites (Campana 2003; Lasaponara \& Masini 2007; Parcak 2009: 97-99; Agapiou et al. 2013). In the case of large sites where high-resolution, multispectral imagery is available, PCA may be a viable method for analyses at the intra-site scale.

Access to a frequently updated repository of high-resolution imagery is essential for monitoring archaeological sites (Casana 2015), but such repositories currently only provide access to panchromatic imagery. A disadvantage to our approach lies in the cost of multispectral WorldView-2 imagery. DigitalGlobe insists on minimum purchases of $25 \mathrm{~km}^{2}$, covering an area much larger than the size of any one archaeological site. Large portions of the purchased image will therefore not be of interest to the researcher focused on specific sites. If the cost and minimum purchase size decrease, or if multispectral products are added to high-resolution repositories, our semi-automated method could be quickly applied to multiple images of different dates in order to track changes in looting patterns (C) Antiquity Publications Ltd, 2017 
over time. A record of these changes and patterns can provide an insight into the scale and nature of organised looting.

The methodology presented here has allowed us to quantify successfully the scale of looting at sites in Afghanistan, but it must be used in tandem with other archaeological and cultural heritage tools. Looting is only one type of damage to sites. Damage to standing architecture and encroachment by agriculture and other harmful activities require other types of assessment. Where possible, it is essential that ground-truthing accompanies remote efforts to analyse looting.

The rapid, rigorous quantification of the extent of looting at Ai Khanoum presented here provides a model that can be applied at a broad regional scale and that can make a major contribution to the documentation of heritage destruction in Afghanistan and other countries. Manual tallies of pit numbers and the area that they cover would take countless hours and be subject to various types of human error. The ability to document and quantify quickly and accurately the numbers and areas of looting pits allows cultural heritage stakeholders and authorities to lobby more effectively for resources and intervention. Our semi-automated method is both feasible and efficient, a useful addition to the cultural heritage toolkit that provides future avenues for both tracking damage to archaeological sites over time, and for communicating the massive scale and effects of looting across the Middle East to the public in quantitative terms.

\section{Acknowledgements}

The work presented in this paper was carried out in the Center for Ancient Middle Eastern Landscapes (CAMEL) at the Oriental Institute of the University of Chicago. Funds provided by the Afghan Heritage Mapping Partnership Grant from the US Department of State have supported the application of the method to archaeological sites in Afghanistan. We thank the Director of the Oriental Institute, Gil Stein, for his support and encouragement. We also thank Morag Kersel for helpful methodological discussions.

Author contributions: AL and JC designed the research and developed the methodology within the context of a broader project directed in 2014 by SB, and in 2014-2016 by EH. AL, JC and EH wrote the article.

\section{References}

Agapiou, A., D. Alexakis, A. Sarris \& D. Hadjimitsis. 2013. Orthogonal equations of multi-spectral satellite imagery for the identification of un-excavated archaeological sites. Remote Sensing 5: 6560-86. https://doi.org/10.3390/rs5126560

Al Quntar, S., K. Hanson, B.I. Daniels \& C. Wegener. 2015. Responding to a cultural heritage crisis: the example of the Safeguarding the Heritage of Syria and Iraq Project. Near Eastern Archaeology 78: 154-60. https://doi.org/10.5615/neareastarch.78.3.0154

Altaweel, M. 2005. The use of ASTER satellite imagery in archaeological contexts. Archaeological Prospection 12: 151-66. https://doi.org/10.1002/arp.254

Bernard, P. 1967. Ai Khanum on the Oxus: a Hellenistic city in central Asia. Proceedings of the British Academy 53: 71-95.
Bjørgo, E., G. Boccardi, E. Cunliffe, M. Fiol, T. Jellison, W. Pedersen \& C. Saslow. 2014. Satellite-based damage assessment to cultural heritage sites in Syria. Geneva: United Nations Institute for Training and Research.

Campana, S. 2003. Ikonos-2 multispectral satellite imagery to the study of archaeological landscapes: an integrated multi-sensor approach in combination with 'traditional' methods, in M. Doerr \& A. Sarris (ed.) The digital heritage of archaeology. CAA2002. Computer applications and quantitative methods in archaeology. Proceedings of the $30^{\text {th }}$ CAA Conference, Heraklion, Crete, April 2002: 219-25. Athens: Hellenic Ministry of Culture.

Casana, J. 2014. Regional-scale archaeological remote sensing in the age of big data: automated detection versus brute force methods. Advances in Archaeological Practice 2: 222-33.

https://doi.org/10.7183/2326-3768.2.3.222 
- 2015. Satellite imagery-based analysis of archaeological looting in Syria. Near Eastern Archaeology 78: 142-52.

https://doi.org/10.5615/neareastarch.78.3.0142

Contreras, D.A. 2010. Huaqueros and remote sensing imagery: assessing looting damage in the Virú Valley, Peru. Antiquity 84: 544-55. https://doi.org/10.1017/S003598X0006676X

Contreras, D.A. \& N. Brodie. 2010. The utility of publicly available satellite imagery for investigating looting of archaeological sites in Jordan. Journal of Field Archaeology 35: 101-14. https://doi.org/ 10.1179/009346910X12707320296838

Cunliffe, E. 2013. Satellites and site destruction: an analysis of modern impacts on the archaeological resource of the ancient Near East. Unpublished PhD dissertation, Durham University.

DigitalGlobe Corporation. 2010. Radiometric use of WorldView-2 imagery. Westminster (CO):

DigitalGlobe. Available at: https://dg-cms-uploadsproduction.s3.amazonaws.com/uploads/document/ file/104/Radiometric_Use_of_WorldView2_Imagery.pdf (accessed 2 May 2017).

- 2013. Data sheet: WorldView-2. Westminster (CO): DigitalGlobe. Available at: https://dg-cms-uploadsproduction.s3.amazonaws.com/uploads/document/ file/98/WorldView2-DS-WV2-rev2.pdf (accessed 2 May 2017).

Hanson, K. 2011. Ancient artifacts and modern conflict: a case study of looting and instability in Iraq, in P.G. Stone (ed.) Cultural heritage, ethics and the military. Martlesham: Boydell \& Brewer.

-2012 . Considerations of cultural heritage: threats to Mesopotamian archaeological sites. Unpublished $\mathrm{PhD}$ dissertation, University of Chicago.

Hesse, R. 2015. Combining structure-from-motion with high- and intermediate-resolution satellite images to document threats to archaeological heritage in arid environments. Journal of Cultural Heritage 16: 192-201. https://doi.org/ 10.1016/culher.2014.04.003

Hill, A.C., Y. Rowan \& M. Kersel. 2014. Mapping with aerial photographs: recording the past, the present, and the invisible at Marj Rabba, Israel. Near Eastern Archaeology 77: 182-86. https://doi.org/10.5615/neareastarch.77.3.0182

Hritz, C. 2008. Remote sensing of cultural heritage in Iraq: a case study of Isin. The American Academic Research Institute in Iraq Newsletter 3: 1-8.

- 2014. Contributions of GIS and satellite-based remote sensing to landscape archaeology in the Middle East. Journal of Archaeological Research 22: 229-76. https://doi.org/10.1007/ s10814-013-9072-2
Kersel, M.M. \& A.C. Hill. 2015. Aerial innovations: using drones to document looting. Oriental Institute News and Notes 224: 8-9.

Lasaponara, R. \& N. Masini. 2007. Improving satellite QuickBird-based identification of landscape archaeological features through tasseled cap transformation and PCA, in Proceedings of the $21^{\text {st }}$ CIPA Symposium in Athens, Greece, June 2007: 812-16. Athens: CIPA.

- 2010. Facing the archaeological looting in Peru by using very high-resolution satellite imagery and local spatial autocorrelation statistics.

Computational Science and Its Applications-ICCSA 2010: 254-61.

Lasaponara, R., G. Leucci, N. Masini \& R. Persico. 2014. Investigating archaeological looting using satellite images and GEORADAR: the experience in Lambayeque in north Peru. Journal of Archaeological Science 42(C): 216-30. https://doi.org/10.1016/j.jas.2013.10.032

Lillesand, T.M., R.W. Kiefer \& J.W. Chipman. 2004. Remote sensing and image interpretation. New York: Wiley \& Sons.

Martinez-Seve, L. 2014. The spatial organization of Ai Khanoum, a Greek city in Afghanistan. American Journal of Archaeology 118: 267-83. https://doi.org/10.3764/aja.118.2.0267

Menze, B.H. \& J. UR. 2012. Mapping patterns of long-term settlement in northern Mesopotamia at a large scale. Proceedings of the National Academy of Sciences of the USA 109: E778-87. https://doi.org/10.1073/pnas.1115472109

PARCAK, S. 2009. Satellite remote sensing for archaeology. London: Routledge.

Parcak, S., D. Gathings, C. Childs, G. Mumford \& E. Cline. 2016. Satellite evidence of archaeological site looting in Egypt: 2002-2013. Antiquity 90: 188-205. https://doi.org/10.15184/aqy.2016.1

SAlopeK, P. 2014. Drones: archaeology's newest tool to combat looting. National Geographic, 13 April 2014. Available at: http://news.nationalgeographic.com/ news/2014/04/140411-drones-jordan-dead-sealooting-archaeology/ (accessed 2 May 2017).

Saturno, W., T. Sever, D. Irwin, B. Howell $\&$ T. Garrison. 2007. Putting us on the map: remote sensing investigation of the ancient Maya landscape, in J. Wiseman \& F. El-Baz (ed.) Remote sensing in archaeology: interdisciplinary contributions to archaeology: 137-60. New York: Springer. https://doi.org/10.1007/0-387-44455-6_6

STEIN, G.J. 2015. The war-ravaged cultural heritage of Afghanistan: an overview of projects of assessment, mitigation, and preservation. Near Eastern Archaeology 78: 187-95. https://doi.org/10.5615/neareastarch.78.3.0187

(C) Antiquity Publications Ltd, 2017 
Stone, E. 2008. Patterns of looting in southern Iraq. Antiquity 82: 125-38. https://doi.org/10.1017/S0003598X00096496

VAn Ess, M., H. Becker, J. Fassbinder, R. Kiefl, I. LiNGENFELDER, G. SCHREIER \& A. Zevenbergen. 2006. Detection of looting activities at archaeological sites in Iraq using Ikonos imagery, in J. Strobl, T. Blaschkle \& G. Griesebner (ed.) Angewandte Geoinformatik; Beiträge zum 18: AGIT-Symposium, Salzburg: 669-78. Heidelberg: Wiechmann.
Wolfinbarger, S., J. Drake, E. Ashcroft \& K. Hanson. 2014. Ancient history, modern destruction: assessing the current status of Syria's World Heritage Sites using high-resolution satellite imagery. Available at:

http://www.aaas.org/page/ancient-history-moderndestruction-assessing-current-status-syria-s-worldheritage-sites-using (accessed 2 May 2017).

Received: 6 June 2016; Accepted: 20 September 2016; Revised: 29 January 2017 